\title{
Happy Voyage: Application of Total Quality Management-TQM in Indian Tourism Industry with specific reference to Uttarakhand
}

\author{
Ankur Kukreti', Ram Singh ${ }^{1}$, Rohit Bansal ${ }^{2}$ * \\ 1. School of Business \& Management Quantum University Roorkee India. \\ 2. Department of Management Studies Vaish College of Engineering Rohtak India. \\ *Corresponding Author Email: rohitbansal.mba@gmail.com
}

\begin{abstract}
In this paper author has tried to find out the factors hampering the development of Tourism sector in India. Author has used the extensive literature survey in order to find out the factors affecting tourism sector. For the smooth development of the tourism sector these factors need to be sorted out but in real life all of the factors can't be sorted as it requires huge investment and would lead to mismanagement of funds. So bringing this thing into concern creator has utilized a conventional procedure where numerous approaches are vieing for consideration for example Pareto Analysis. Pareto Analysis is an innovative perspective on of issues since it animates thinking and sort out musings. This system encourages creator to distinguish the main 20 percent of makes that requirements be routed to determine the 80 percent of the issues. The estimation of the Pareto Principle for creator is that it reminds you to concentrate on the 20 percent of things that issue. of the things you do during your venture, just 20 percent are extremely significant. Those 20 percent produce 80 percent of your outcomes. Recognize and spotlight on those things first, however don't thoroughly overlook the staying 80 percent of causes. Author has used a self-designed questionnaire to detect the frequency of all important causes that hampers the development of Tourism sector from a group of 100 respondents from Dehradun. By plotting the response of the respondents on Pareto Chart author has tried to find out and has detected the most important factors that requires immediate concern to speed up the development of tourism sector.
\end{abstract}

Keywords: Tourism Sector, Mismanagement, Pareto Analysis, Pareto Chart.

Article Received: 05 June $2020 \quad$ Revised: 16 June $2020 \quad$ Accepted: 28 June 2020

\section{Introduction}

PM Narendra Modi has been promoting Indian tourism everywhere throughout the world however ground the truth is that because of different reasons the previous year has seen an extremely disturbing log jam in vacationer entries into India and an alarming slowdown for majority of tour operators.

Official figures from the Govt. of India may demonstrate a few increments, yet the real circumstance is different from facts and figures. Indian tourism is facing a negative growth due to various reasons. Travel and the travel industry have not quite recently ended up being one of the world's greatest businesses but on the other hand is solid and reliable area. In the region of 1990 and 2000, vacationer arrivals by and large created at a typical pace of 4-3 percent for every annum. Travel and the travel industry address approximately 11 percent of the general GDP, as showed by the World Travel and Tourism Council. World Tourism Organization predicts one billion overall appearances in the year 2010 and will persistently increase till 2020, overall vacationer appearances to Asia and Pacific locale has been extended by more than 400 percent progression from 105 million of each 2000 to 438 million till 2016. As the world is being introduced the data age, assignment of the data and "Information and Communication Technology (ICT)" is quickly developing. Web has changed the world into a general town that can be explored at the snap of a mouse. It outfits expected pioneers 
with quick access to printed and visual alteration on targets all through the world. The Internet has correspondingly changed into a basic mechanical gathering in "Business to Business (B2B) and Business to Consumer (B2C)" exchanges, the apportioning of things, structures association of business relates, and are speedy procedures for getting to learning on a wide extent of subjects including travel and the movement business data.

Information is quickly available each moment of consistently and at the ensuing expense to pull in purchasers to choose progressively taught choices. In any case, most significant actuality is that are there any position to investigate the genuineness of these information and how well government is supporting the business so as to make it prosper around the world. In this paper author has focused on such growth barriers by the use of extensive literature to extract the reasons hampering the growth of tourism. In order to find the solution to these questions author has applied techniques of "Total Quality Management (TQM)" named "Pareto analysis and Fishbone diagram".

\section{Literature Review}

Shreekumar and Parayil [1], demonstrated that notwithstanding the way that the territory of Kerala in India has been seen as a 'model of headway', its achievements may unravel by virtue of a huge gathering of internal what's progressively, external issues. The organization and the association currently adventure the travel industry as 'an engine of improvement' a splendid wellspring of outside exchange and business to revive the local economy. Limitation to tremendous scope the travel industry stretches out by regular and work activists are habitually overseen through undemocratic suggests.

This article centers to a not as much as chipper part for the travel industry in the local economy and the movement that work to exaggerate the travel industry's idea in the economy in a rising setting of authoritative frustration, political crisis and interest gather association. Exercises are pulled in to come back to the common contention on the travel industry what's more, improvement. Be that as it may, the anticipated photo of a developing imperativeness in the tourism part in Kerala distinct difference a glaring difference to the general situation of the poor execution of the tourism business in India, and in South Asia when all is said in done. Is Kerala a special case as the experts guarantee? We investigate this situation by setting Kerala's execution against the bigger background of tourism flow as experienced in Third World nations by and large and South Asia specifically.

Joshi et.al [2], demonstrated an examination utilized a cross-country board information model to research the relative commitments of sociopolitical, regular and social attributes and national tourism strategies to worldwide tourism development. Worldwide tourism receipt information were balanced for nation particular swelling and afterward investigated in connection to institutionalized measures of the World Economic Forum's "mainstays of tourism intensity."

Results showed that global tourism receipts are more receptive to arrangements and controls favoring tourism, wealth of common assets, lavishness in social legacy, and wellbeing and cleanliness than they are to foundation, security, value aggressiveness, and different factors. Discoveries feature key elements related with global tourism receipts and give a general system that could educate approaches and administration techniques intended to advance supportable universal tourism improvement. investigates the motivational measurements and basic nourishment utilization in tourism, and to look at the impacts of two above mentioned measures related identity characteristics are considered, to do this specific nourishment neophobia and assortment chasing, on these motivational measurements were used.

A traveler nourishment utilization motivational scale was created and seven motivational measurements were recognized: curiosity and assortment, credible experience and eminence, relational and culture, value/esteem and affirmation, wellbeing concern, nature and dietary pattern, and tangible and relevant joy. Both sustenance neophobia and assortment looking for were found to affect different motivational measurements. The ramifications of the discoveries for training and future research were examined. K. Czernek [3] distinguished and described determinants of learning 
exchange and assimilation coming about because of the particular highlights of tourism, and additionally to demonstrate their results for participation between partners in a traveler district. Applying a made reasonable system and contextual analysis approach "a mountain visitor area in the south of Poland", five gatherings of determinants are distinguished: the mastery of little and medium-sized ventures, the discontinuity and assorted variety of supply, professional reinforces, possession specificity and the territorial/nearby character of tourism.

The creator demonstrates how these determinants block learning exchange and assimilation, and thusly for the most part adversely influence participation. D. Buhalis [4] Data progresses (ITs) win all components of indispensable and operational organization. As information is the spirit of the travel industry, ITs give the two open entryways and challenges to the business. Notwithstanding the weakness experienced in the enhancements of ITs in the travel industry, the "primary reliable will be change".

Consistently, affiliations and destinations, which need to battle, will be compelled to process. But on the off chance that the current the movement business redesigns its capacity, by using the rising ITs and inventive association techniques, there is a peril for exogenous players to enter the business network, risking the circumstance of the current ones. Essentially imaginative and innovative providers will be able to persevere through the limitation in the new thousand years. This paper gives a structure to the usage of headway in the movement business by getting a handle on a key point of view.

A perpetual business process re-building is proposed so as to guarantee that an expansive grouping of necessities, for example, vision, balanced alliance, commitment and preparing are set up, so they can empower destinations what's more, principals to abuse the outstanding open passages climbing through ITs. J Kandampully [5] The centralization of this paper is to separate the fittingness of the utilization of "organization bundling", an idea orchestrated to do being gotten by the movement business relationship to help them in their propelling push beyond what many would consider possible with request, and the possibility of associations offered with that of adventurers' needs. It is proposed here that social occasion of bundling renders it valuable for advantage relationship to oversee request distinction while, at the same time, offering associations which will constantly meet client needs.

This paper presumes that purchaser steadfastness can be upgraded if pilgrims' needs what's more, need are considered amidst the outline of the movement business packs advanced. A travel industry affiliation's indispensable decision to get customer arranged thoughts will ensure the convincing organization of benefits. Sönmez et. al. [6] while guests are permitted to keep up a key good ways from objectives related with possibility, the results of horrifying events on voyager objectives are unavoidable and can be critical.

Dread mongering those destinations the travel industry can be viewed as a failure for an objective and following events can make a certifiable the travel industry crisis. This article fights that voyager objectives especially those unprotected against politically stirred viciousness should join crisis organization orchestrating into their general sensible improvement and promoting organization frameworks to guarantee and remake their image of prosperity, to support potential visitors of the security of the zone, to reestablish the territory's helpfulness/offer, and to assist neighborhood with voyaging and the travel industry people in their monetary recovery.

Proposals consolidate having a crisis organization configuration set up, developing a travel industry crisis organization group, developing a crisis organization manual, and banding together with law prerequisite specialists. Cockerell N [7] gave six factors affecting international as well as domestic tourism. They are:

- "Lack of economic incentives"

- "Lack of understanding of the nature of tourism"

- "Insufficient buying power in domestic tourism"

- "Inadequate accommodation"

- "Damage to historical and archeological 
sites"

- Others

\section{Research Methodology}

In this paper author has applied Pareto Analysis to detect the major factors hampering the development of tourism in India. Pareto Analysis states that 80 percent of the defects are caused because of major 20 percent reasons. If we somehow we are able to control those 20 percent reasons then we will be able to eliminate 80 percent defects and controlling above stated 20 percent causes will require less investment, less man power and less time to ensure us a qualityfull result. Moreover fishbone diagram is used to reach to the root cause of any problem.

\section{Primary Data}

Field survey of 100 respondents to find out the frequency of occurrence of each factor.

\section{Secondary Data}

Use of extensive literature survey to dig out the cause for downfall of Indian tourism.

\section{Sample Size}

100

\section{Sampling Technique}

Simple random technique

\section{Analysis}

There are various factors that are hampering the development of Indian tourism sector and these factors are:

Table 1: Challenges faced by Indian Tourism Industry

\begin{tabular}{|c|c|}
\hline S.N. & Challenges \\
\hline 1. & A: "Lack of economic incentives" \\
\hline 2. & B: "Lack of understanding of the nature of tourism" \\
\hline 3. & C: "Insufficient buying power in domestic tourism" \\
\hline 4. & D: "Inadequate Accommodation" \\
\hline 5. & E: "Damage to historical and archeological sites" \\
\hline 6. & F: Others \\
\hline
\end{tabular}

Table 2: Reponses based on field survey by Respondents

\begin{tabular}{|c|c|c|c|c|c|c|}
\hline SN & Denotations & $\begin{array}{c}\text { Frequency } \\
\text { of } \\
\text { Responses }\end{array}$ & $\begin{array}{c}\text { Cumulative } \\
\text { Count }\end{array}$ & $\begin{array}{c}\text { Cumulative } \\
\%\end{array}$ & $\begin{array}{c}\mathbf{8 0} \% \\
\text { Rule }\end{array}$ & Changes \\
\hline 1. & A & 25 & 25 & 25 & 80 & "Lack of economic incentives" \\
\hline 2. & B & 20 & 45 & 45 & 80 & $\begin{array}{c}\text { "Lack of understanding of the } \\
\text { nature of tourism" }\end{array}$ \\
\hline 3. & C & 18 & 63 & 63 & 80 & $\begin{array}{c}\text { "Insufficient buying power in } \\
\text { domestic tourism" }\end{array}$ \\
\hline 4. & D & 12 & 75 & 75 & 80 & "Inadequate Accommodation" \\
\hline 5. & E & 13 & 88 & 88 & 80 & "Damage to historical and \\
archeological sites"
\end{tabular}

These responses are plotted on a Pareto Chart in order to find the most important reasons that needed to be focused first.

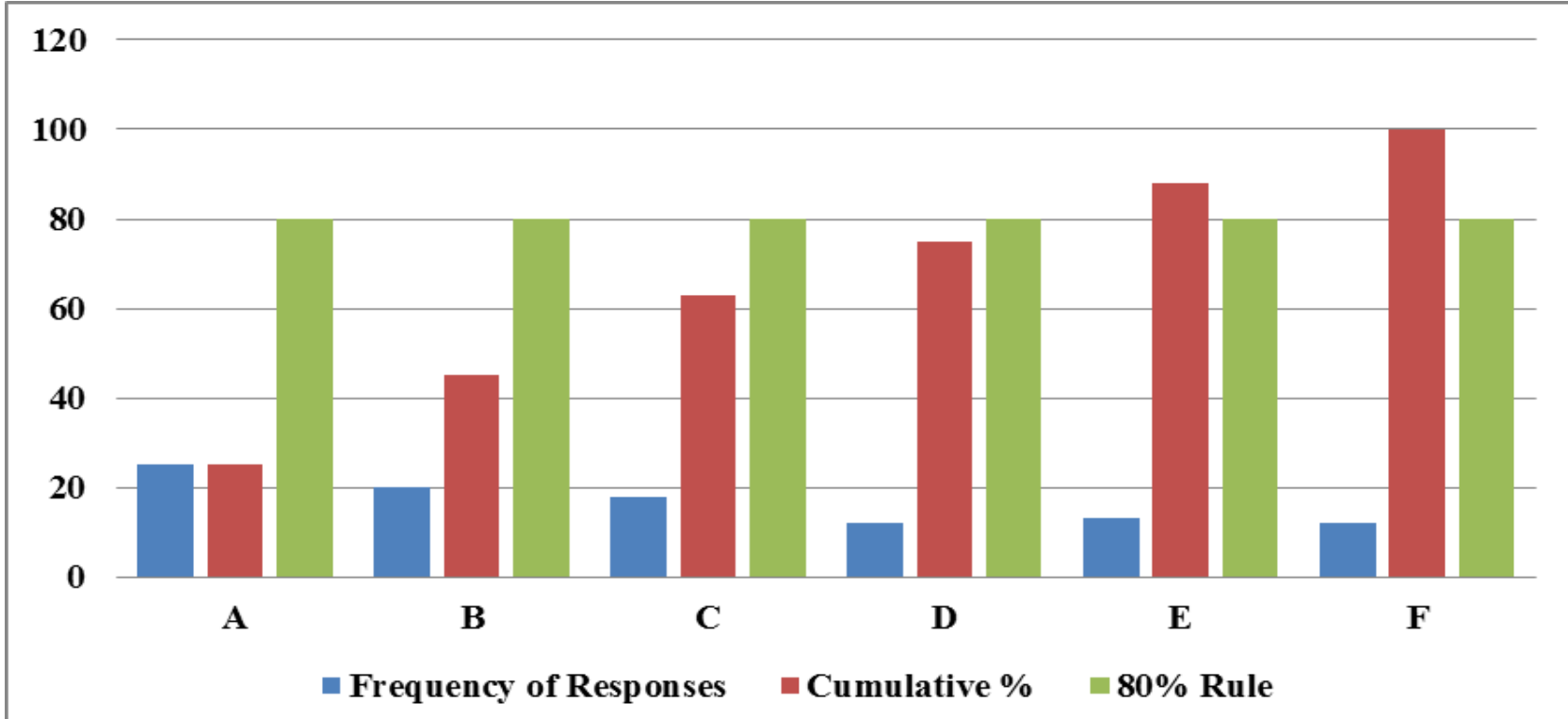

Figure 1: Pareto Chart of the problems faced by Indian tourism industry 
Based on the Pareto Chart it is found that reasons denoted by $\mathrm{A}, \mathrm{B}, \mathrm{C}$ and $\mathrm{E}$ are the reasons to be focused first and these reasons are as follows:

- "Lack of economic incentives"

- "Lack of understanding of the nature of tourism"
- "Insufficient buying power in domestic tourism"

- "Damage to historical and archeological sites"

These reasons were then plotted on fishbone diagram to reach to the root cause.

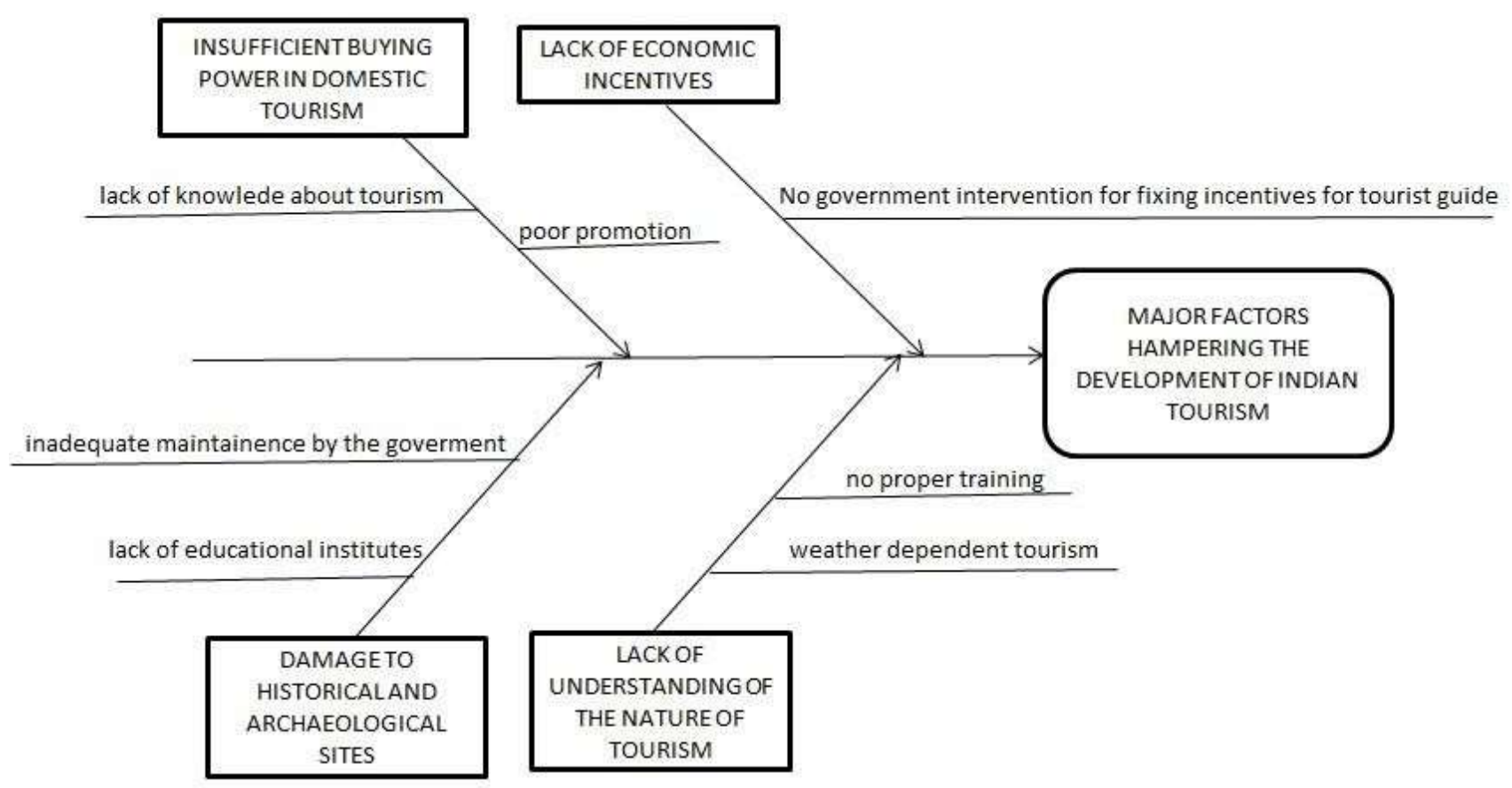

Figure 2 1: Fishbone Diagram of Challenges faced by Indian tourism industry

So based on the combination of all the root cause it is evident above mentioned factors i.e.

- No government intervention

- No proper training

- Weather dependent tourism

- Poor promotion

- Lack of knowledge about tourism

- Inadequate maintenance of historical and archeological site by the government

- Lack of educational institutes Are the factors that are hampering the growth of Indian tourism with specific reference to Uttarakhand.

\section{Result and Conclusion}

On the basis of the above observation it is seen that if we amalgamate these numerous causes and form a single cause that leads to the downfall of Indian Tourism is Lack of government support and inadequate funding provided by government and its inattentive nature towards tourism are the reasons for failure of Indian tourism. Therefore we can say that for the betterment of Indian tourism government should take essential measures and act as a supportive authority for generating sustainable and reliable revenue [8-9].

\section{References}

1.Sreekumar TT, Parayil G (2002) Contentions and contradictions of tourism as development option: the case of Kerala, India. Third World Quarterly, 23(3):529548.

2.Joshi O, Poudyal NC, Larson LR (2017) the influence of sociopolitical, natural, and cultural factors on international tourism growth: a cross-country panel analysis. Environment, Development and Sustainability, 19(3):825-838.

3.Czernek K (2017) Tourism features as determinants of knowledge transfer in the process of tourist cooperation. Current Issues in Tourism, 20(2):204-220.

4.Buhalis D (1998) Strategic use of information technologies in the tourism 
industry. Tourism management, 19(5):409421.

5.Kandampully J (2000) the impact of demand fluctuation on the quality of service: a tourism industry example. Managing Service Quality: An International Journal, 10(1):10-19.

6.Sönmez SF, Apostolopoulos Y, Tarlow P (1999) Tourism in crisis: Managing the effects of terrorism. Journal of travel research, 38(1):13-18.

7.Cockerell N (1990) Factors Affecting
Tourism. In: Quest M. (eds) Horwath Book of Tourism. Palgrave Macmillan, London.

8.Gupta V, Das Gupta D (2008) Adoption and Use of ICT in Indian Tourism: Interventions for the top tourist destination of India.

9.Mak AH, Lumbers M, Eves A, Chang RC (2017) the effects of food-related personality traits on tourist food consumption motivations. Asia Pacific Journal of Tourism Research, 22(1):1-20. 